\title{
Fracture mechanics of PVDF polymeric material : specimen geometry effects
}

\author{
L. Laiarinandrasana ${ }^{(1)}$, G. Hochstetter ${ }^{(2)}$, M. Lafarge ${ }^{(3)}$
}

(1) Centre des Matériaux (UMR CNRS 7633) Ecole Nationale Supérieure des Mines de Paris BP

87, F-91003 Evry Cedex - FRANCE

e-mail : lucien.laiarinandrasana@ensmp.fr

(2) ARKEMA - Centre d'Etude de Recherches et de Développement (CERDATO) F-27470

Serquigny - FRANCE

e-mail : gilles.hochstetter@arkemagroup.com

(3) ARKEMA - CRRA - Rue Henri Moissan BP 63, F-69493 Pierre Bénite Cedex - FRANCE

e-mail : melanie.lafarge@arkemagroup.com

\begin{abstract}
Polyvinylidene fluoride (PVDF) is a semi-crystalline polymer that has been widely studied for structural applications, because it exhibits good mechanical properties and chemical resistance. During viscoplastic deformation, the material whitens after the onset of necking due to nucleation and growth of voids. Mechanical tests on cracked specimens show the crack instability on DENT specimens whereas stable crack growth on SENB specimens is also encountered. In the global approach of non linear fracture mechanics framework, the two-parameter approach indicates that according to the opening stress state in the remaining ligament, the crack growth can be more or less stable. Namely, tensile crack specimens such as DENT favour instabilities whereas bending specimens (like SENB) are proved to present stable cracking. This work deals with computing Q-stresses on DENT and SENB specimens with the help of FE modelling. The material toughness $J_{I C}$ is then determined by means of experimental data gathered with both specimens. $J_{I C}$ depends on the specimen geometry. A $J_{I C}-Q$ curve is then plotted for the PVDF material at $20^{\circ} \mathrm{C}$.
\end{abstract}

\section{INTRODUCTION}

Polyvinylidene fluoride (PVDF) is a semi-crystalline polymer that has been widely studied for its piezoelectric properties [1], due to its polar $\beta$ phase. Nevertheless, the apolar phase, $\alpha$, is also studied for structural applications, because it exhibits good mechanical properties and chemical resistance [2]. During viscoplastic deformation, the material whitens after the onset of necking due to nucleation and growth of voids, as evidenced using small and large angle X-Ray diffraction [2]. In this study, an a-PVDF grade used for offshore applications is analysed at $20^{\circ} \mathrm{C}$ with respect to viscoplastic and damage behaviour. Double Edge Notch Tensile (DENT) as well as Single Edge Notch Bending (SENB) specimens were used in order to investigate sensitivity of toughness to the specimen geometry. A numerical simulation of these tests is performed using the Gurson Tvergaard Needleman (GTN) model [3-5] which was adapted to the present material. This model allows to ensure that the local stresses are correctly determined. In addition, $\mathrm{J}$ integral values can be calculated. By using the small scale yielding (SSY) concept, the second parameter $Q$ can be obtained. The motivation is to investigate whether there exist a single $J_{I C}-Q$ curve as is the case for metallic materials.

\section{EXPERIMENTS}

\subsection{Material and specimens}

The material of interest was provided by ARKEMA and is generally used in multilayered offshore risers. In this work the PVDF under study differs from the standard industrial grade since it was extruded without plasticizer. Therefore, a significant porosity has been noted: the initial defect population was estimated by microscopic examination followed by image analysis, of a PVDF sample broken in liquid nitrogen. The porosity is equal to $10 \%$ consisting of $1 \mu \mathrm{m}$ diameter 
voids which are always observed in bulk PVDF and that are created during crystallisation and extrusion [1] ; a second, much smaller $(0.1 \mu \mathrm{m})$ population is also observed in the investigated material.

Double edge notched specimens were tested in tension (DENT). They were machined from $12 \mathrm{~mm}$ thick extruded PVDF sheets (ASTM D638 M1). The length is $110 \mathrm{~mm}$, the width (W) is $6 \mathrm{~mm}$ and the thickness is $12 \mathrm{~mm}$. Various crack length (a) and width ratios ( $\mathrm{a} / \mathrm{W}$ ) are used ranging from 0.25 to 0.5 . The cracks are made with a cutter blade. Special attention is paid to guarantee alignment of both cracks. Initial crack lengths are measured from the fracture surfaces using an optical microscope. DENT tests are carried out at constant crosshead speed $\left(0.15 \mathrm{mms}^{-1}\right)$, and a gage extensometer (gauge length: $6.2 \mathrm{~mm}$ ) is used to monitor the crack opening displacement (COD).

Single edge notched specimens (SENB) were tested in three point bending at a constant displacement rate $(0.15 \mathrm{~mm} / \mathrm{s})$ using an Inströn machine. Specimens were tested using a span-to-specimen width ratio, S/W, of 4:1. Width (W) and thickness $(B)$ are respectively $14 \mathrm{~mm}$ and $7 \mathrm{~mm}$, and the a/W ratio was 0.5 . Displacement and load are monitored together with the crack opening displacement measured using a MTS extensometer.

\subsection{Tests on cracked specimens}

6 tests were selected in this work in order to investigate the crack inititiation characteristics regardless of the stableness of the crack growth see table 1. For DENT specimens the imposed displacement rate was applied by controlling either the machine crosshead $(110 \mathrm{~mm})$, or the extensometer $(6.2 \mathrm{~mm})$.

Table I. Selected tests for this study

\begin{tabular}{|c|c|c|c|}
\hline Specimen & $\mathrm{a} / \mathbf{W}$ & $\begin{array}{l}\text { Displacement rate } \\
\left(0.15 \mathrm{mms}^{-1}\right) \text { on }\end{array}$ & Crack growth \\
\hline Ag12 DENT1 & 0.46 & Crosshead (110mm) & Unstable \\
\hline Ag5 DENT2 & 0.25 & Crosshead (110mm) & Unstable \\
\hline Ag6 DENT3 & 0.38 & Crosshead (110mm) & Unstable \\
\hline Ag37 DENT4 & 0.23 & Extensometer (6.2mm) & Unstable \\
\hline Ag 32 DENT5 & 0.43 & Extensometer $(6.2 \mathrm{~mm})$ & Stable \\
\hline SENB & 0.5 & hammer & Stable \\
\hline
\end{tabular}

The produced experimental curves are illustrated in figure 1 where the load is plotted against the Crack Opening Displacement (COD). Stable crack growth was observed on DENT5 and SENB as indicated in table 1 and figure 1 by the load decrease at the final stage of the tests.

Figure 2 shows some pictures taken during the tests. Prior to crack initiation, the material in the vicinity of the crack tip whitens. In this zone, it has been observed that there is a significant void growth inducing inter-void fibrils stretching. It is assumed to be the crazed area. The crack starts growing at the back of the craze. This event appears at the maximum load for stable crack whereas for unstable crack growth it corresponds to the final experimental point of the test. In the following, the crack initiation will refer to these characteristic points.

In fact, in the process zone, two phases of material are in presence : the craze and the "sound" material. Since the crack tip is first located at the back of the craze, the stability of the crack growth can be defined by the ability of this crack tip, according to its speed, to reach the craze tip. The fracture surfaces of unstable crack clearly indicate two patterns. 

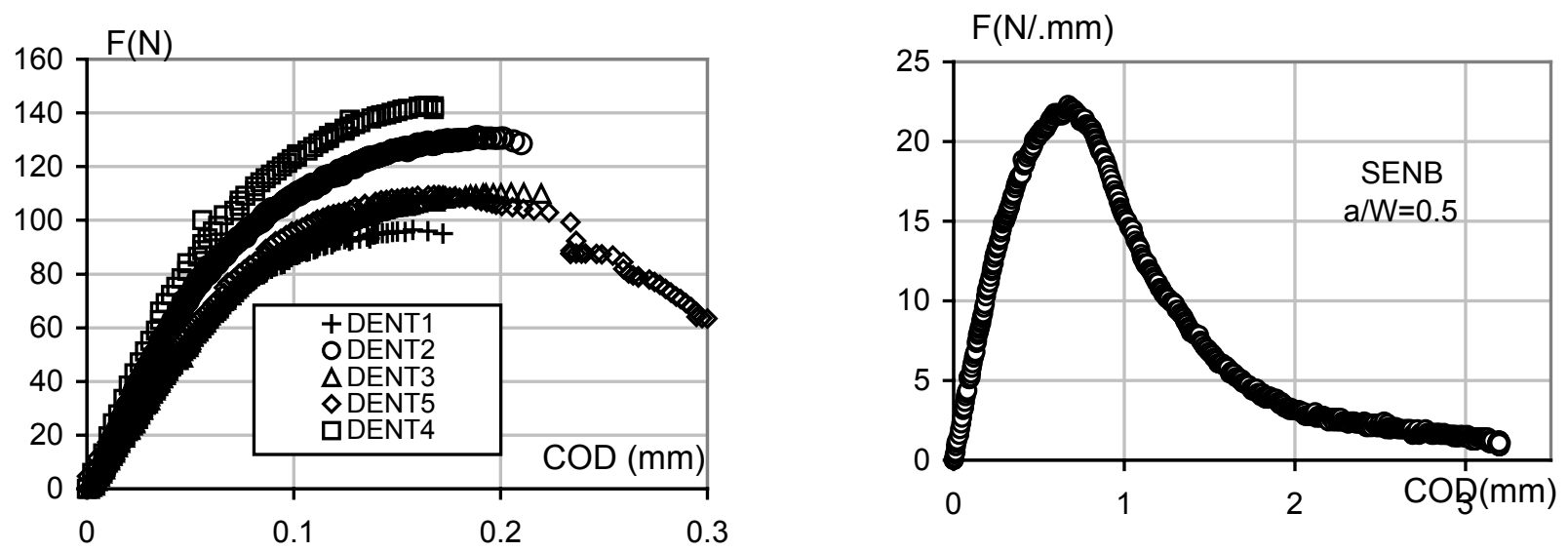

Figure 1 : Load versus COD curves of DENT and SENB tests

The first one is related to when the crack tip goes through the crazed material in a ductile manner, with deformed fibrils. The second one is concerned with brittle aspects when the crack tip has reached the crazed zone and evolves in the "sound" material. For stable crack growth, the crack tip is always embedded in the crazed zone during the test.
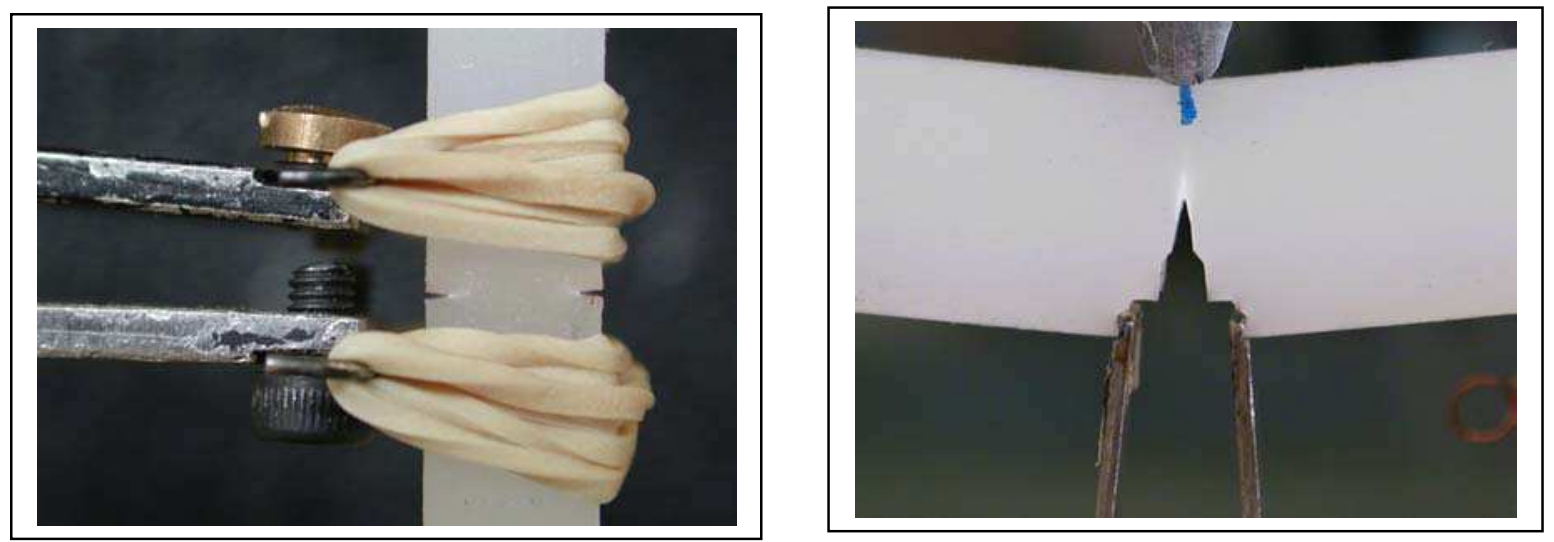

Figure 3 : Whitening due to void growth in the vicinity of the crack tip

\section{Global approach}

\subsection{First attempt}

The global approach of the Fracture Mechanics concept is based on load parameters such as :

- $\quad$ the stress intensity factor $(K)$ or the Energy release rate $(G)$ for linear elasticity;

- $\quad$ and J-integral for the non linear material behaviour.

The figure 1 clearly indicates the non linear relationship between the load and the crack opening displacement (COD). $K$ and $G$ will then be ignored in the following.

The J-integral concepts require that the stress-strain curve be modelled by a power law function (Ramberg-Osgood). The so-called plastic material coefficients have to be identified. For the PVDF under study the stress-strain curve exhibits a kind of plateau. This is presumably due to viscous effects (strain rate dependence) and void growth during the craze formation. Consequently, the Ramberg-Osgood coefficients cannot be determined either with the stress-strain curve, or with the load-COD plot by using an inverse optimisation method.

Since the goal is to determine the limitation of the global approach of the Non Linear Fracture Mechanics (NLFM) concepts, we will use the Finite Element (FE) analysis to capture the maximum information concerning the selected tests

\subsection{Gurson-Tvergaard-Needleman model}


As mentioned previously, the process zone is concerned with two material phases : the craze and the "sound" one. The use of the mechanics of porous media has been attempted in [1] where notched and cracked specimens were utilised in order to investigate void development over a wide range of loading conditions. A numerical simulation of these tests is performed using a modified Gurson-Tveergard-Needleman (GTN) model [3-5], which was adapted to the present material. The yield surface is expressed as:

$$
\Phi\left(\sigma, \sigma^{*}, f\right)=\frac{\sigma_{e q}^{2}}{\sigma^{*}}+2 q_{1} \cdot f \cdot \cosh \left(\frac{q_{2} \sigma_{k k}}{2 \sigma^{*}}\right)-1-q_{1}^{2} f^{2} \stackrel{\text { def. } \sigma^{*}}{=} 0
$$

$\sigma_{\text {eq }}$ is the Von Mises stress, and $\sigma_{k k}$ the trace of the stress tensor. $f$ is the porosity, $q_{1}$ and $q_{2}$ are model parameters. $q_{2}$ was expressed as a function of the maximum principal plastic strain $p_{1}$. Details of the present model are reported in reference [1].

The GTN model allows to run FE analyses on the DENT end SENB specimens. For DENT specimen, 2D quadratic isoparametric elements under plane strain (PE) conditions were used to model $1 / 4$ of the specimen. Each specimen was meshed according to its a/W ratio and the gauge length $(110 \mathrm{~mm}$ or $6.2 \mathrm{~mm})$. For the SENB test, half of the specimen was meshed corresponding to $\mathrm{a} / \mathrm{W}=0.5$, but the striker as well as the support were also modelled and the contact between the PVDF and these metallic components was accounted for with a friction coefficient of 0.2 .

Figure 4 shows good agreement between simulated and experimental load versus COD curves, at least for DENT specimens. For SENB, the used PE condition is not so satisfactory. 3D simulations were performed in [1], but for the present work we just restrict investigations to $2 \mathrm{D}$ consideration. FE computations were carried out only until the crack initiation defined previously.
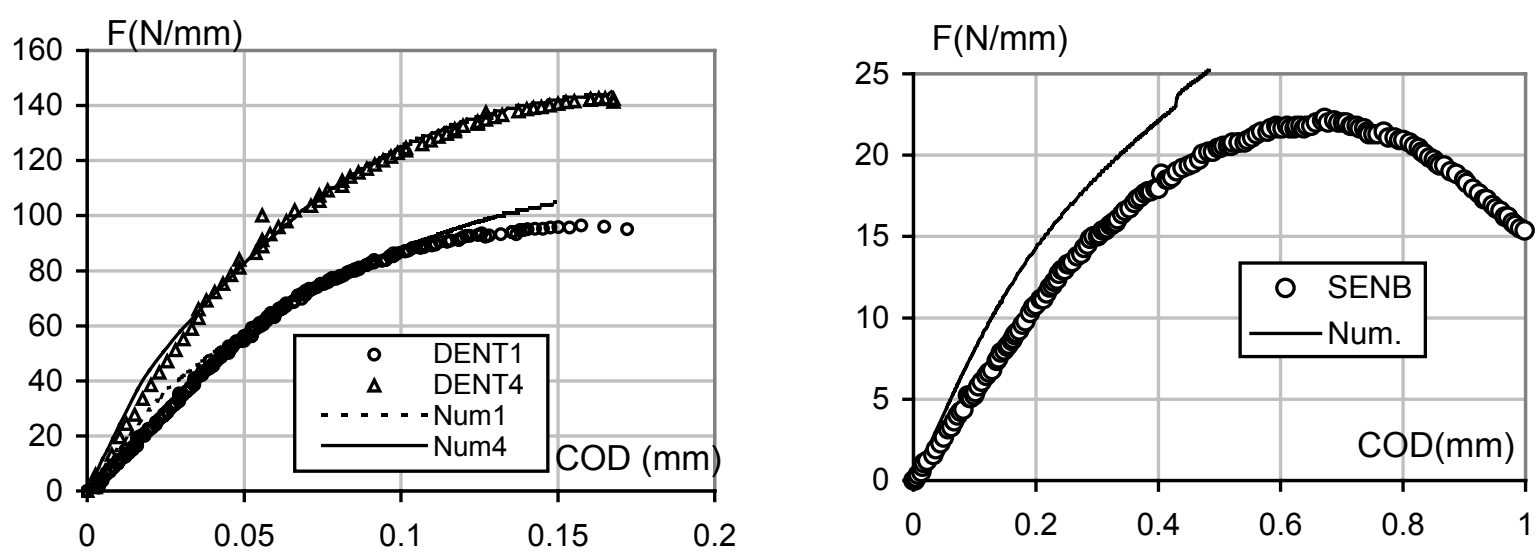

Figure 4 : Comparison between numerical and experimental load versus COD curves for DENT and SENB

The idea is here to take benefit of this relevant modelling in order to extract the global approach of the NLFM parameter. For instance the Z-set FE code [6] is provided with J-integral computation by using the De Lorenzi [7] approach. The Jintegral is then calculated throughout the loading step and especially its value at the crack initiation is supposed to be the toughness $\mathrm{J}_{\mathrm{IC}}$. J-integral value has been demonstrated to be path independent. Due to symmetry the numerical values of $\mathrm{J}$ are multiplied by 4 for DENT specimens and by 2 for SENB specimens.

The $\mathrm{J}_{\mathrm{IC}}$ values are plotted in figure 5 according to the a/W ratios and the kind of loading. In this figure, "Long" and "Short" refer to the distance of application of the displacement for DENT specimens as previously discussed. $J_{I C} v s$ a/W representation has been used by Sumpter and Forbes [8] for metallic materials in order to investigate both effects of a/W 
ratios for the same specimen type and the specimen geometry (DENT vs SENB) on toughness $\mathrm{J}_{\mathrm{IC}}$. It turns out that the same trend as in metallic material is observed concerning both effects:

- $\quad$ for long DENT, $\mathrm{J}_{\mathrm{IC}}$ decreases when a/W increases, the stabilised $\mathrm{J}_{\mathrm{IC}}$ being obtained for long cracks $(\mathrm{a} / \mathrm{W}>$ 0.4). This effect is not reflected by short DENT data;

- $\quad$ for approximately the same $a / W=0.5, J_{I C}(S E N B)$ is much lower than $J_{I C}(D E N T)$. This effect has motivated the two parameter approach [9] based on the loss of constraint and that will be developed further.

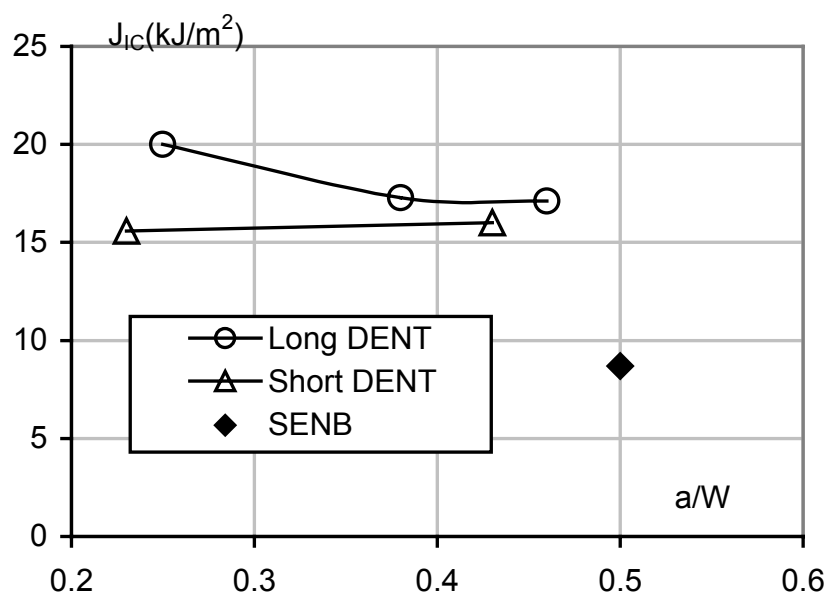

Figure 5. $\mathrm{J}_{\mathrm{IC}}$ values according to the a/W ratio

It should be mentioned that surprisingly, the values of toughness obtained for stable crack growth specimens are lower than those for unstable ones. So, unstable crack does not imply brittle fracture. In both cases, crack initiation occurs in a ductile manner in the crazed zone. Then for DENT specimens, there is a crack acceleration that provokes the brittle failure at the end of the test. This is not observed in metallic materials.

\subsection{Q-parameter}

In the global approach of NLFM, the two-parameter concept [9] has been used in order to account for specimen geometry effects. Typically, cracked specimen geometries are classified as flexural or tensile specimen according to the opening stress state in the ligament.

In figure 6, the opening stresses calculated by FE method are plotted as a function of the distance from the crack tip for both specimen geometries (DENT and SENB). These curves were obtained at the step corresponding to the crack initiation. For DENT specimen, the opening stress $\left(\sigma_{22}\right)$ is positive in the whole ligament, whereas for SENB approximately one half of the ligament is subjected to compressive (negative) stress. Consequently the SENB is considered to be a flexural specimen. This kind of geometry (like Compact Tension (CT) specimen) is often used to characterise fracture criterion since it provides a low (hence conservative) value of toughness.

The trend of the stress singularity can be analysed as follows. The arrows indicate the extent of the crazed zone corresponding numerically to the material where the porosity is greater than the initial value of $10 \%$. The maximum stress of about $70 \mathrm{MPa}$ is representative of the craze tip for both geometries. For the crack tip (at the back of the craze) the maximum opening stress is about 90MPa for DENT specimen and $80 \mathrm{MPa}$ for SENB specimen. The intermediate maximum stress between the aforementioned maxima corresponds to the region, in the crazed zone, where the stress triaxiality ratio is maximum. This information is necessary to the definition of the second parameter. 

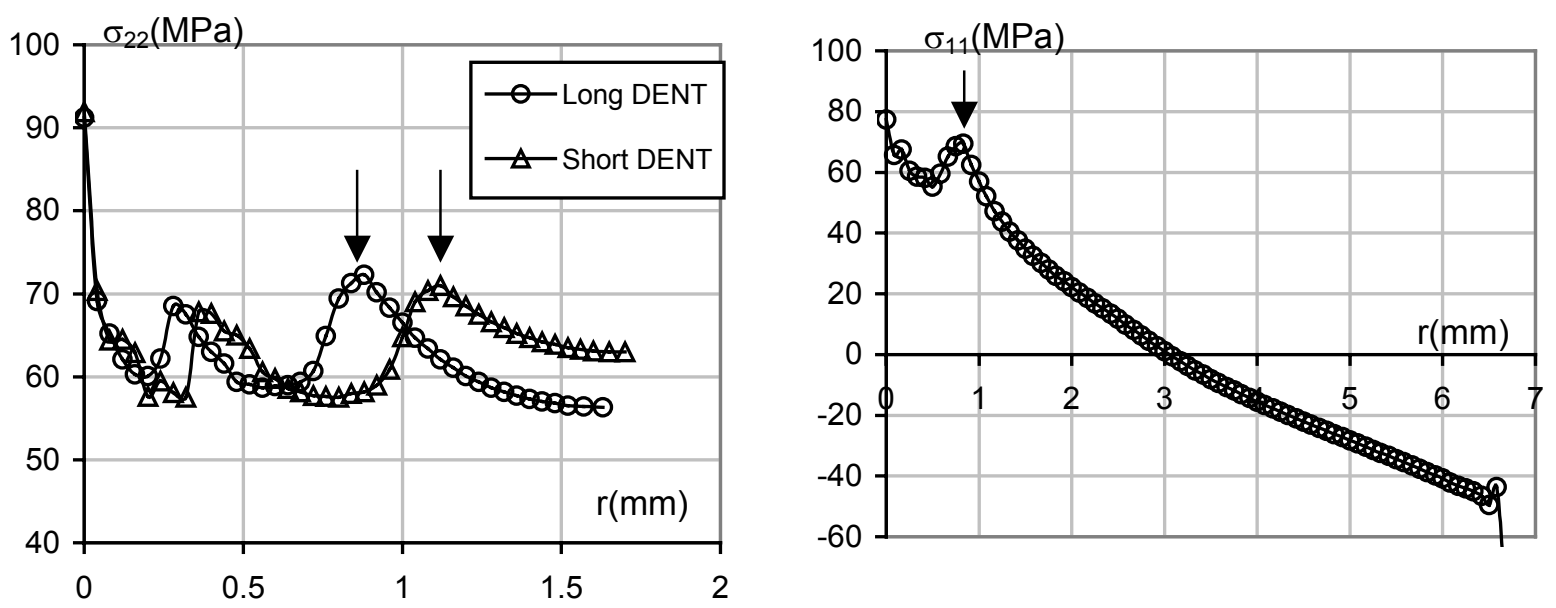

Figure 6. Opening stress singularities for DENT and SENB specimens ( $r$ distance to crack tip, $\sigma_{11}\left(r e s p \sigma_{22}\right)$ opening stress for SENB (resp. DENT))

Following O'Dowd and Shih [10-11] the second parameter (called Q-parameter) is defined as :

$$
\mathrm{Q}=\frac{\sigma_{\mathrm{FE}}-\sigma_{\mathrm{ref}}}{\sigma_{0}}
$$

where

$\sigma_{0}$ is the yield stress, in this work its value is $50 \mathrm{MPa}$;

$\sigma_{\mathrm{FE}}$ is the opening stress calculated by FE method;

$\sigma_{\text {ref }}$ is a reference stress generally obtained by using the Hutchinson-Rice-Rosengren (HRR) stress field [12-13].

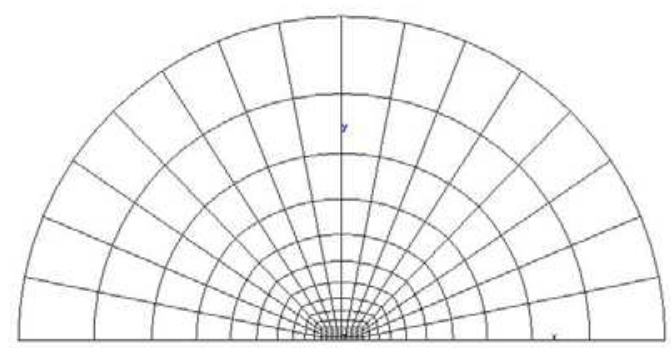

Figure 7 : Meshing used for SSY stress calculation

Since Ramberg-Osgood coefficients are not available, the HRR stress field cannot be calculated. We then suggest to take the small scale yielding (SSY) opening stress as reference stress. The SSY stress is obtained by FE method on a semi-circular mesh (figure 7) surrounding the crack tip (boundary layer) and by applying a displacement field corresponding to linear fracture mechanics concept (K-field). For each specimen, the $\mathrm{K}$ value used in $\mathrm{K}$-field is given by the formula :

$$
K=\sqrt{\frac{E J_{I c}}{\left(1-v^{2}\right)}}
$$

where $E=2000 \mathrm{MPa}$ is the Young's modulus whereas $v=0.38$ is the Poisson ratio of the PVDF material. 
Figure 8 shows some examples of $\mathrm{J}$-integral histories where the loading rate is taken to be as similar as possible for the real specimen and the K-field. This is required since the material exhibit viscous effects.
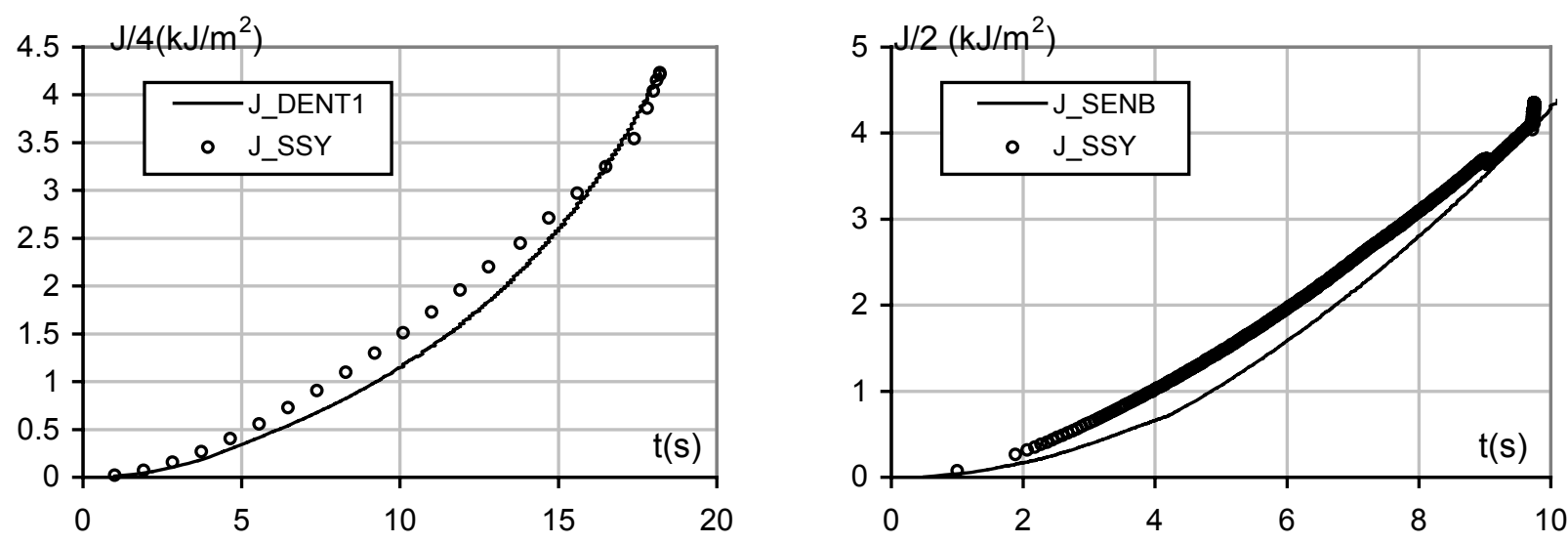

Figure 8 : Comparison of $\mathrm{J}$ integral histories for both specimen geometries
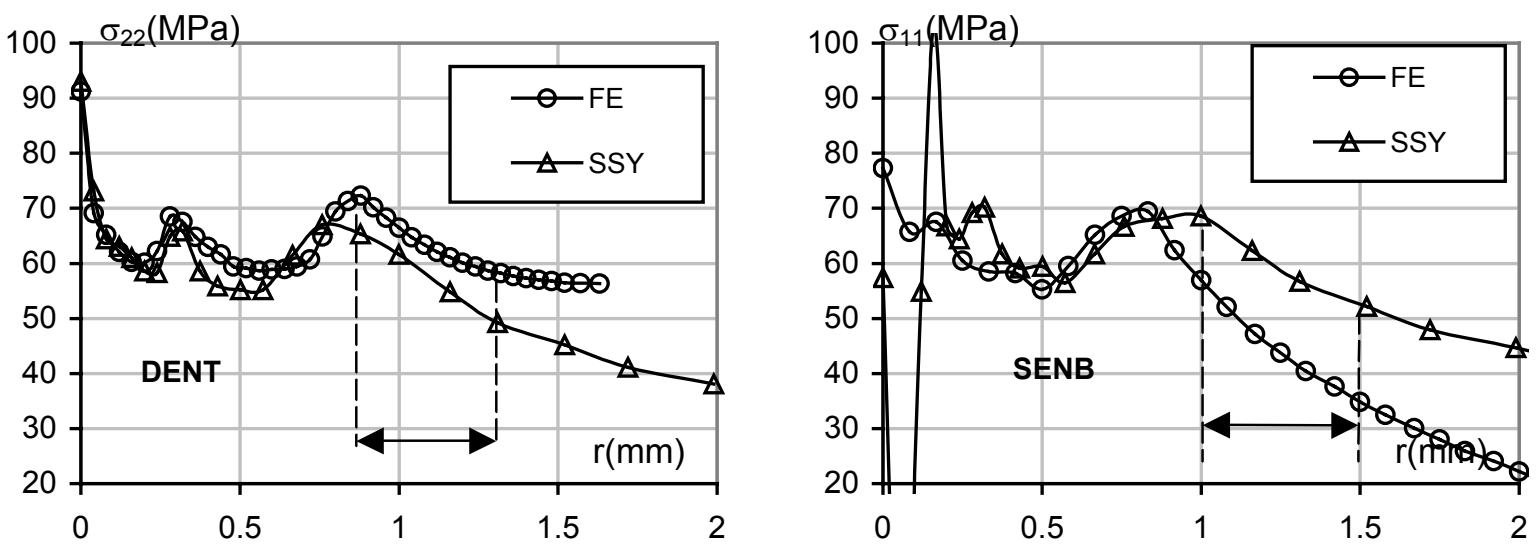

Figure 9. Comparison between $\sigma_{\mathrm{FE}}$ and $\sigma_{\mathrm{SSY}}$ for DENT and SENB specimens
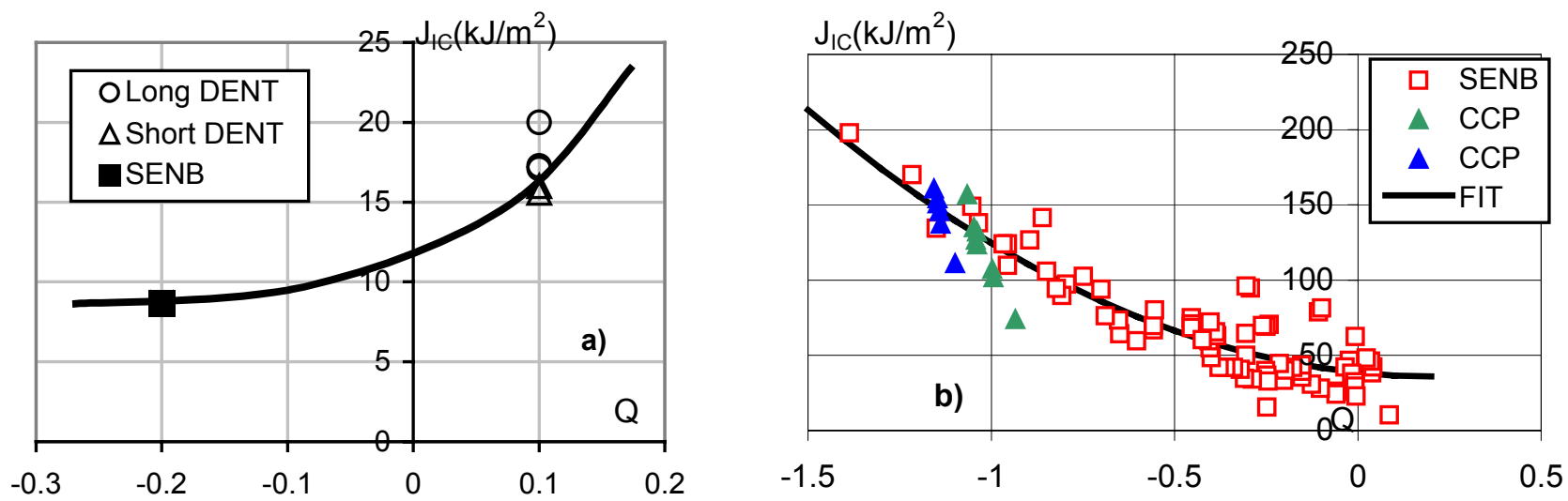

Figure 10. $J_{I C}-Q$ curves a) for PVDF material at $20^{\circ} \mathrm{C}$, b) for metallic material according to [8]

The determination of $Q$ values consists in plotting together both $\sigma_{\mathrm{FE}}$ and $\sigma_{\mathrm{SSY}}$, then equation (2) is applied. Figure 9 illustrates the comparison between $\sigma_{\mathrm{FE}}$ and $\sigma_{\mathrm{SSY}}$. It is observed that $\sigma_{\mathrm{FE}}>\sigma_{\mathrm{SSY}}$ for DENT specimen. Therefore $Q$ parameter in this case is positive. Conversely, for SENB specimen, $\sigma_{\mathrm{FE}}<\sigma_{\mathrm{SSY}}$. By taking the $\left(\sigma_{\mathrm{FE}}-\sigma_{\mathrm{SSY}}\right)$ quantity at about $1 \mathrm{~mm}$ from the crack tip (at the tip of craze), we can determine the $Q$ values. For all of our $D E N T$ specimens $Q \approx 0.1$ whereas for SENB $Q \approx-0.2$. These values allow to plot the $J_{I C}-Q$ curve in figure 10a) for PVDF material. This trend is 
opposed to what is known for metallic materials (figure 10b). In [7] and [8], flexural specimens exhibit positive $Q$ whereas negative value of $Q$ are often encountered in tensile specimens. It is to be mentioned that present $Q$ values are determined at the tip of the craze whereas for metallic materials, since there is no crazed zone, $Q$ is related to the crack tip. In addition, the global approach of NLFM is based on a homogeneous material. In the PVDF polymeric material under study, the crazed zone represents a second phase which can embed the fracture processes.

\section{CONCLUSION}

Polyvinylidene fluoride (PVDF) is a semi-crystalline technical polymer due to its good mechanical properties and chemical resistance. Subjected to deformation, the material whitens due to nucleation and growth of voids. Double Edge Notch Tensile (DENT) as well as Single Edge Notch Bending (SENB) specimens were used in order to investigate the geometry effects on the toughness. Tensile cracked specimen such as DENT favours instabilities whereas bending specimens (like SENB) are proved to present stable cracking.

J-integral formulae cannot be applied for this material since no power law coefficients can be indentified. In fact, the damage and fibrils streching in the material induce a plateau in the stress-strain curve. By using a modified Gurson Tvergaard Needleman (GTN) model, the crazed zone can be modelled and the J-integral can be computed at the crack tip by using this GTN model. The material toughness $J_{I C}$ is then determined by means of experimental data gathered with both specimens. Surprisingly, the values of toughness obtained for stable crack growth specimens are lower than those for unstable ones. Q-stresses values on DENT and SENB specimens were calculated with the help of FE results. The trend of $J_{I C}-Q$ curve for the PVDF material at $20^{\circ} \mathrm{C}$ differs from what is observed for metallic material.

\section{REFERENCES}

[1] Challier, M., Besson, J., Laiarinandrasana, L. and Piques, R. "Damage and Fracture of Polyvynilidene Fluoride (PVDF) at $20^{\circ} \mathrm{C}$ : experiments and modelling" Engineering. Fracture Mechanics, 73:79-90. 2006.

[2] Castagnet S, Girault S, Gacougnolle JL, Dang P. "Cavitation in strained PVDF : mechanical and X-ray experimental studies. Polymer.41(20):7523-7530; 2000.

[3] Gurson AL. "Continuum theory of ductile rupture by void nucleation and growth": Part 1-yield criteria and flow rules for porous ductile media. J Eng Mat Tech. 99:2-15; 1977.

[4] Tvergaard V. "Influence of voids nucleation on ductile shear fracture at a free surface" J Mech Phys Solids. 30:399425; 1982.

[5] Tvergaard V, Needleman A. "Analysis of the cup-cone fracture in a round tensile bar" Acta Metal. 32:157-169; 1984.

[6] Besson, J., and Foerch, R.,"Large scale object-oriented finite element code design". Computer Methods in Applied Mechanics and Engineering 142, 165-187; 1997.

[7] De Lorenzi, H.G. "Energy release rate calculations by finite element method" Engineering. Fracture Mechanics, 21(1):129-143; 1985.

[8] Sumpter, J.D.G., Forbes, A.T. " Constraint based analysis of shallow cracks in mild steel" Proceedings of TWI/AWI/IS International Conference on Shallow Crack Fracture Mechanics, Toughness tests and applications, paper 7, September 1992.

[9] O'Dowd N.P. and Shih, C.F. "Two-parameter fracture mechanics : theory and applications" Fracture Mechanics : Twenty fourth volume, ASTM STP 1207, ed. J.D Landes, D.E. Mc Cabe, J.A.M. Boulet, pp. 21-47, 1994.

[10] O'Dowd N.P. and Shih, C.F. "Family of crack-tip fields characterized by a triaxiality parameter I. Structure of fields" Journal of the Mechanics and Physics of Solids, Vol. 39, n 8 pp. 989-1015, 1991.

[11] O'Dowd N.P. and Shih, C.F. "Family of crack-tip fields characterized by a triaxiality parameter II. Fracture applications" Journal of the Mechanics and Physics of Solids, Vol. 40, n 5 pp. 939-963, 1992.

[12] Hutchinson, J.W., "Singular behaviour at the end of a tensile crack tip in a hardening material" Journal of the Mechanics and Physics of Solids, Vol. 16, pp. 13-31, 1968.

[13] Rice, J.R., Rosengren, G.F., "Plane strain deformation near a crack tip in a power law hardening material" Journal of the Mechanics and Physics of Solids, Vol. 16, pp. 1-12, 1968.

[14] O'Dowd N.P., Shih, C.F., Dodds, R.H. " The role of geometry and crack growth on constraint and implications for ductile/brittle fracture" Constraint effects in Fracture : Theory and Applications, Vol. 2, ASTM STP 1244, ed. M. Kirk, Ad Bakker, Philadelphia, pp. 134-159; 1995. 